\title{
Avaliação da Aprendizagem: a construção de uma proposta em Educação Física
}

\author{
MARIA AUGUSTA GEBARA GORINI \\ Centro Universitário Filadélfia - UNIFIL/Londrina \\ magorini@hotmail.com \\ NADIA APARECIDA DE SOUZA \\ Professora da Universidade Estadual de Londrina - UEL \\ nadia@uel.br
}

\begin{abstract}
Resumo
Visando a orientar um novo fazer avaliativo e enunciar alternativas para o profissional da disciplina de Ginástica Rítmica na construção de uma prática avaliativa que assuma a função de subsidiar os processos de ensino e aprendizagem, contribuindo para a formação de um profissional reflexivo, desenvolveu-se pesquisa participante com 35 alunos da disciplina de Ginástica Rítmica do Curso de Graduação em Educação Física da UEL. Os procedimentos de pesquisa envolveram o estudo e análise de: referencial teórico e documental, representações simbólicas feitas pelos alunos, observações diretas, questionários e os procedimentos avaliativos implementados. A avaliação se efetivou de maneira a favorecer que as aprendizagens ocorressem e contribuíssem para o bom desempenho dos alunos. Assim, promoveram-se as condições para uma reflexão que proporcionou: a identificação e superação das dificuldades encontradas; o acolhimento de uma nova concepção de avaliação, entendida como informativa e subsidiária do ensinar e do aprender; a apropriação de conhecimentos indispensáveis à formação do futuro educador; a aproximação entre teoria e prática; a assunção, pelo aluno, de seu papel de coresponsável pelo curso de suas aprendizagens, dentre outros.

Palavras-chave: avaliação da aprendizagem, formação docente, profissional reflexivo.
\end{abstract}

\section{Resumen}

Pretendiendo orientar un nuevo hacer evaluativo e enunciar alternativas para el profesional de la asignatura de Gimnástica Rítmica em la construcción de una práctica evaluativa que asuma la función de subsidiar los procesos de enseñanza y aprendizaje, contribuiendo para la formación de un profesional reflexivo, se ha desarollado uma investigación participante, com 35 alumnos de la asignatura de Gimnástica Rítmica del Curso de Licenciatura en Educación Física de la Universidad Estadual de Londrina (UEL). Los procedimientos de investigación envolvieran el estudio y análisis de: referencial teórico y documental, representaciones simbólicas hechas a los alumnos, observaciones directas, cuestionários y los procedimientos evaluativos implementados. La evaluación se efectivó de manera a favorecer que los aprendizajes ocurriesen y contribuiessen para el buen disempeño de los alumnos. Asi, se promovieron las condiciones para una reflexión que proporcionó: la identificación y superación de las dificultades encontradas; el acojimiento de uma nueva concepción de evaluación, entendida como informativa e subsidiária del enseñar y del aprender; el apoderamiento de conocimentos indispensábles a la formación del futuro 
educador; la aproximación entre teoria y prática; la asunción, por el alumno, de su papel de co-responsáble por el curso de sus aprendizajes, entre otros.

Palabras-clave: evaluación del aprendizaje, formación dociente, profesional reflexivo.

\begin{abstract}
In order to guide a new way of engaging in assessment and offering alternatives for the teacher of Rhythmic Gymnastics in constructing an assessment practice meant to subsidize the teaching and learning processes, contributing to create a reflective professional, a participant research was conducted with 35 students of Rhythmic Gymnastics at the undergraduate course in Physical Education at the State University of Londrina. The research procedures involved the study and analysis of: theoretical and documental material, symbolic representations made by the students, direct observations, questionnaires and the implemented assessment procedures. The assessment was carried out so as to promote the learning process and contribute to the students' good performance. Thus, conditions were created for a reflection which provided: the identification and overcoming of difficulties detected; the acceptance of a new conception of assessment, understood as informative and subsidiary to the teaching and learning processes; the appropriation of essential knowledge to form the future educator; the approximation between theory and practice; the students' acceptance of their role as co-responsible for their learning process, among others.
\end{abstract}

Key words: learning assessment, teacher education, reflective professional. 


\section{DESCORTINANDO ASPIRAÇÕES E DESCREVENDO CAMINHOS}

Ante os múltiplos desafios do futuro, a educação surge como um trunfo indispensável à humanidade na construção dos ideais da paz, da liberdade e da justiça social. Temos na educação um caminho, entre outros e para além deles, que conduz a um desenvolvimento humano mais harmonioso, mais autêntico, que faz recuar a pobreza, a exclusão social, as incompreensões, as opressões, as guerras e outros males das mais variadas ordens.

No final do século XX, tão marcado quer pela agitação e pela violência, quer pelos progressos econômicos e científicos, no alvorecer de um novo século, cuja aproximação nos deixava indecisos entre a angústia e a esperança, impõe-se que todos os responsáveis prestem atenção às finalidades e aos meios da educação.

Mesmo diante da importância da educação, as políticas educativas não têm a prioridade que deveriam. Em nosso país houve, nos últimos tempos, um aumento do número de crianças e jovens que tiveram acesso ao ensino. Entretanto, muitos deles, que são matriculados na escola, não concluem o curso, e mesmo aqueles que permanecem nem sempre têm uma formação adequada que eleve o seu patamar cultural.

Evidencia-se, dessa forma, a necessidade de uma postura mais reflexiva em relação aos rumos do processo educacional. A prática que se concretiza nas escolas tem sido, muitas vezes, determinante de êxitos e fracassos, exercendo um papel antidemocrático no processo de escolarização: o minguado percentual estatístico da população brasileira que tem acesso à escola torna-se menor ainda quando nos colocamos diante dos dados de evasão e repetência escolar (Luckesi, 1999, p. 63).

Educadores e até políticos têm assumido lutas em prol da denúncia da função seletiva e discriminatória das notas e conceitos e dos sérios prejuízos decorrentes da reprovação de estudantes das classes populares, tentando encaminhar a questão de maneira a eliminar o fenômeno da reprovação. Tais medidas procuram minimizar o prejuízo social decorrente da concepção de avaliação como função burocrática, punitiva, e obstaculizante ao projeto de vida de nossas crianças e adolescentes (Hoffmann, 2000a, p. 16).

A prática avaliativa constitui-se num obstáculo à aprendizagem quando as dimensões do pensar e do fazer pedagógico não se articulam com perspectivas que promovam o acompanhamento do processo de construção do conhecimento vivenciado pelo aluno, tendo em vista a superação dos problemas e dificuldades de aprendizagem.

A Educação Física foi incluída, inicialmente, nos currículos de alguns Estados brasileiros no início do século $\mathrm{XX}$, tornando-se prática 
educativa obrigatória apenas em 1937, quando foram feitas as primeiras referências explícitas à área em textos constitucionais.

Atualmente, tratando-se da disciplina Educação Física, os parâmetros curriculares consideram que a avaliação deva ter utilidade, tanto para o aluno como para o professor, para que ambos possam dimensionar os avanços e as dificuldades do processo de ensino e aprendizagem e torná-lo cada vez mais produtivo (Brasil, 1997).

Marcada pelo tempo e pelas formas de pensamento de cada época, a disciplina Educação Física traz influências autoritárias e inflexíveis, bem como de esporte de competição e recordes em sua história, que, quando presentes no contexto escolar, descaracterizam a sua dimensão educativa.

Em decorrência, tivemos - e ainda temos - durante anos, a Educação Física na escola, privilegiando uma visão tecnicista e, portanto, objetivando o rendimento esportivo, a formação de atletas e, em conseqüência, promovendo a exclusão dos alunos "menos" habilidosos e "pouco" aptos fisicamente, quando seu foco de interesses deveria incidir sobre o diagnóstico das aprendizagens efetivadas e sobre a delimitação das falhas a serem superadas no decorrer das relações de ensino e aprendizagem, comprometendo-se com a superação das dificuldades encontradas na apropriação do conhecimento.

Destarte, atitudes e valores implícitos à disciplina há tempos, e presentes ainda hoje nas práticas educativas, estão transformando a educação física escolar numa atividade desestimulante, segregadora e até aterrorizante, principalmente para os alunos considerados menos capazes ou não aptos, ou que não estejam decididos pelo rendimento esportivo (Soares et al., 1994, p. 100).

Estar-se-ia repetindo o quadro em que aqueles que não possuíam grandes habilidades em determinadas práticas esportivas eram prejudicados na avaliação; era a exclusão dos ditos "menos aptos" fisicamente, corroborando a idéia de que a avaliação tradicional, não satisfeita em criar fracassos, empobrece as aprendizagens e induz, nos professores, didáticas conservadoras e, nos alunos, estratégias utilitaristas (Perrenoud, 1999, p. 18).

As dificuldades inerentes à prática avaliativa, aliada a um processo cristalizado de compreender e exercitar o ensino, a aprendizagem e a avaliação no campo da Educação Física, suscitaram o seguinte questionamento: propor uma nova forma de efetivar a avaliação da aprendizagem, pela implementação de diferentes ferramentas e com o uso de seus resultados numa perspectiva diagnóstico-formativa, contribuirá para que os alunos sejam favoráveis à avaliação, gerando uma reflexão que proporcione identificar e superar as suas dificuldades?

Assim, este estudo tem por objetivo orientar um novo fazer avaliativo e enunciar alternativas para o profissional da disciplina de 
Ginástica Rítmica na construção de uma prática avaliativa que, cumprindo sua finalidade educativa, assuma a função de subsidiar os processos de ensino e aprendizagem, contribuindo para a formação de um profissional reflexivo; compreendido como aquele que se constrói, entrelaçando o conhecimento teórico e prático à reflexão crítica sobre a sua própria prática, na busca pela edificação da sua identidade pessoal e profissional, alicerçada no movimento triplo sugerido por Schön da reflexão na ação, da reflexão sobre a ação e da reflexão sobre a reflexão na ação.

$\mathrm{Na}$ construção da resposta ao problema enunciado e para consecução do objetivo estabelecido, muitas ações se fizeram necessárias: pesquisa bibliográfica, pretendendo $\mathrm{o}$ aprofundamento teórico de diferentes aspectos relativos à temática estudada; identificação da concepção de avaliação presente no aluno, antes e depois da implementação da nova proposta avaliativa; proposição de novos instrumentos de avaliação que possibilitassem ao aluno uma maior conscientização acerca das dificuldades que vivencia no decorrer dos processos de ensino e aprendizagem, levando-o a superá-las pela reflexão constante e progressiva; e, promoção de momentos de diálogo e reflexão entre professores responsáveis, professores e alunos, alunos e alunos.

Para realizar este estudo optamos pela abordagem qualitativa, porque uma das grandes postulações da pesquisa qualitativa é a de sua atenção preferencial pelos pressupostos que servem de fundamento à vida das pessoas (Triviños, 1987, p. 130), permitindo, assim, apreender um nível de realidade, bem como delimitar os significados, motivos, aspirações, crenças, valores e atitudes que nos respondem questões muito particulares, principalmente no contexto de um estudo voltado para a consecução de uma prática avaliativa comprometida com a superação de problemas e com o aperfeiçoamento dos processos de ensino e aprendizagem.

No campo dos enfoques qualitativos, a pesquisa participante coloca o pesquisador no meio da cena investigada, atuando na trama da peça. De maneira que [...] privilegia a prática e o propósito transformador do conhecimento que se adquire da realidade que se procura desvendar em seus aspectos essenciais e acidentais, [...] e realizar através da ação um processo de transformação da realidade que interessa (Triviños, 1987, p. 125).

A pesquisa participante é estruturada inicialmente, mas, no decorrer do percurso, diante de novos fatos, ela se reestrutura, busca novos delineamentos condizentes com os achados que venham a conduzi-la à descoberta de outras necessidades e de outras dimensões da realidade, complementando-a ou enriquecendo-a.

Sua perspectiva crítica implica na recusa dos mitos da neutralidade e da objetividade em relação ao pesquisador, exige que ele assuma 
plenamente uma intencionalidade que não se limite a constatar como pensam, falam ou vivem determinadas pessoas, mas busque mergulhar na espessura do real, captar a lógica dinâmica e contraditória do discurso de cada ator social e de seu relacionamento com outros atores, visando despertar nos dominados o desejo da mudança e a elaborar, com eles, os meios de sua realização (Brandão, 1985 , p. 25), favorecendo a compreensão de que,

os fatos sociais não são coisas, mas sim o produto de ações humanas. Os homens e as mulheres fazem a sociedade e da mesma maneira são feitos por ela, podemos entender que somos atores e protagonistas de nossa história da mesma maneira que somos definidos e condicionados por ela. Dentro dessa relação de interação, não há mais lugar para um pesquisador separado de seu objeto de pesquisa. (Brandão, 1985, p. 24)

Dessa maneira, é impossível imaginar uma separação entre o sujeito da pesquisa e o seu objeto, se o sujeito é ele mesmo um ser social, se são as ações humanas que modelam e transformam a sociedade da qual o pesquisador é parte integrante, podendo, inclusive, sofrer as conseqüências do projeto social que propõe ou das transformações que sua ação pode provocar (Brandão, 1985).

$\mathrm{Na}$ pesquisa participante os pesquisadores e os pesquisados são sujeitos de um mesmo trabalho, ainda que com situações e tarefas distintas. Esse tipo de pesquisa favorece ao pesquisador e ao pesquisado conhecerem a sua própria realidade, participarem da produção deste conhecimento e tomarem posse dele, isto é, compreenderem a realidade para poder transformá-la.

A pesquisa participante propicia estudos da realidade com objetivos mais precisos e utilizáveis, de forma que os problemas estudados são os problemas vividos e sentidos pela população pesquisada. Sua preocupação não está em explicar os fenômenos, mas sim em favorecer a aquisição de um conhecimento e de uma consciência crítica do processo de transformação pelo grupo que está vivendo este processo, para que ele possa assumir, de forma cada vez mais lúcida e autônoma, seu papel como protagonista e ator social.

Considerando o propósito da pesquisa, a busca da proximidade da teoria-prática, a necessidade de desvelar a realidade presente na sala de aula nos momentos em que práticas tradicionais são deixadas de lado, abrindo espaço para inovações, sentimos a necessidade da participação da professora e dos alunos para que esta construção fosse coletiva, pautada em situações reais e na busca daquelas delineadas como ideais. Assim, no momento em que as ações foram empreendidas, as reflexões vindas das partes envolvidas subsidiaram as novas ações a serem desenvolvidas, fornecendo os indícios para os delineamentos seguintes. 
Os envolvidos foram o professor responsável pela disciplina de Ginástica Rítmica, $2^{\circ}$ ano, juntamente com os 35 alunos que dela participavam. O estudo ocorreu em 2000 no curso de Educação Física da Universidade Estadual de Londrina.

O desenvolvimento do estudo e a conseqüente coleta de dados envolveram: momentos de estudo e planejamento com o professor responsável pela disciplina, estudo aprofundado do referencial teórico e documental, representações simbólicas, observações do cotidiano, aplicação de questionário e, ainda, construção de um portfólio de avaliação.

Para proceder à análise dos dados foi utilizada a análise dos conteúdos, visto que esta constitui [...] uma técnica de investigação que tem por finalidade a descrição: objetiva, sistemática e quantitativa do conteúdo manifesto da comunicação (Bardin, 1977, p. 36), possibilitando não só compreender o sentido da comunicação expressa, mas também os significados subjacentes por trás das palavras e das ações empreendidas.

As análises se processaram em três etapas: antes da implementação da proposta da avaliação das aprendizagens - pré-análise -, durante o desenvolvimento das atividades propostas - descrição analítica - e, ao final do novo processo avaliativo vivenciado - interpretação referencial -, constituindo dados empíricos da realidade, buscando aproximações do real na relação entre o geral e o particular, entre a teoria e a prática. A definição das categorias temáticas foi resultante da organização dos dados coletados na etapa de pré-análise. Emergiram as seguintes categorias temáticas: sentimentos prevalecentes em face das práticas avaliativas; concepção de avaliação; dicotomia teoria-prática em relação à avaliação das aprendizagens.

\section{NA CONSTRUÇÃO DE UMA PRÁTICA MAIS REFLEXIVA}

Procuramos, na trajetória desse estudo, ter uma visão ampla do significado da avaliação pelo aprofundamento do referencial teórico a compor o cenário de fundo; analisar a visão do aluno, seus anseios, suas necessidades suas dificuldades e limitações, suas expectativas e, principalmente, trabalhar com o re-significar da avaliação no cotidiano da disciplina de Ginástica Rítmica do curso de Licenciatura em Educação Física.

Em momento algum tivemos a pretensão de afirmar a melhor maneira de avaliar nas disciplinas teórico-práticas dos cursos de Educação Física, mas sim de refletir como o cotidiano acadêmico pode mudar com práticas pedagógicas que possibilitem o acompanhamento do processo de 
construção do conhecimento vivenciado pelo aluno, tendo em vista a superação dos problemas e dificuldades de aprendizagem.

Toda a análise veio acompanhada de uma preocupação no sentido de respeitar e de refletir, de forma cuidadosa, sobre as manifestações expressas pelos alunos que participaram da pesquisa, fossem elas evidenciadas no discurso - oral ou escrito - ou observadas na prática desenvolvida no interior da sala de aula.

Os resultados positivos foram inúmeros e decorreram de um trabalho realizado por pesquisadora, professora e alunos que foi desenvolvido na tentativa de mudar a própria história - no que concerne, principalmente, ao saber e ao fazer docente. Assim, no interior da sala de aula, ao edificar um processo de avaliação diferente na disciplina de Ginástica Rítmica:

- A relação entre professor e alunos foi ampliada e intensificada de forma democrática e solidária, gerando um clima de maior confiança e cooperação.

- Os sentimentos de medo, ansiedade e tensão, inicialmente presentes, foram desaparecendo progressivamente à medida que a avaliação como processo se realizava, sendo percebida e compreendida pelos alunos.

- Os instrumentos avaliativos diversificados, assim como as atividades desafiadoras, contribuíram significativamente para a superação das dificuldades encontradas quanto aos sentimentos expressos anteriormente em face das situações avaliativas.

- Os erros manifestos no decorrer do processo de ensino e aprendizagem foram compreendidos como indicadores relevantes para a construção do saber do aluno e da professora, pois todos puderam vivenciar a importância do confronto constante entre o realizado e o almejado, entre o efetivado e o proposto, objetivando a redução das "distâncias" que os separam.

- As atividades, refeitas após a análise das hipóteses construídas pelo aluno, favoreceram as aprendizagens e o aprofundamento dos conhecimentos, pela apropriação de um saber enriquecido e complementado - pela comparação de hipóteses, pela busca de respaldo em referencial teórico, pela troca de experiências, dentre outras.

- As novas tarefas, propostas para cada etapa, mas sempre relacionadas às anteriores, em uma gradação de desafios coerentes às descobertas e às dificuldades encontradas pelos 
alunos, favoreceram que as aprendizagens ocorressem em um processo contínuo e gradual, que respeitou as diferenças individuais e oportunizou novas ocasiões para que cada aluno avançasse em direção à superação do ainda não saber.

- As atividades, centradas na compreensão do movimento e desenvolvidas, portanto, com o intuito de criar condição de execução e não com objetivos de perfeição técnica e de performance, contribuíram para a apropriação de conhecimentos necessários e indispensáveis à formação do futuro professor de Educação Física.

- As tarefas e obstáculos apresentados no decorrer do processo fizeram com que os alunos tomassem consciência de seu próprio funcionamento em relação às aprendizagens e que gerissem seus progressos, favorecendo, portanto, o desenvolvimento da autonomia no âmbito da regulação de suas próprias aprendizagens - auto-regulação - de maneira a propiciar a redução da regulação externa.

- O portfólio, utilizado como ferramenta de avaliação formativa, permitiu ao aluno "olhar" sua trajetória de aprendizagem de forma a perceber sua evolução em relação à apropriação e ao aprofundamento do conhecimento.

- A Oficina de Ginástica Rítmica propiciou o contato com a realidade que se efetiva nas escolas e foi uma atividade que permitiu aos alunos exercitarem a transferência dos conhecimentos adquiridos na disciplina, unindo o saber à experiência e exercitando a relação teoria-prática.

Entretanto, trabalhar com avaliação não foi uma tarefa fácil. As dificuldades se fizeram presentes durante todo o percurso: reduzida carga horária da disciplina, inadequação do tempo disponível para consecução das atividades, estrutura do curso organizada em ano/disciplina e, até, a resistência ao novo por parte de alguns alunos.

$\mathrm{O}$ fato de somente uma disciplina trabalhar de forma diferenciada o processo avaliativo nos fez perceber a importância de propiciar aos professores oportunidades para refletirem em conjunto sobre o significado das ações pedagógicas que desenvolvem e das formas pelas quais implementam o processo avaliativo. As transformações são muito mais complexas e difíceis - se não impossíveis - quando as ações que as engendram são solitárias, pois podemos pouco solitariamente, mas... muito se conquista solidariamente. 
Assim, faz-se necessário a promoção de espaços e tempos para a interlocução e a partilha de saberes e fazeres entre os docentes que atuam no curso de Educação Física, visando a oferecer condições que propiciem: a análise de concepções teóricas e perspectivas metodológicas, a permuta de experiências e de vivências implementadas, a construção e reconstrução das práticas, a promoção de ações e intervenções mais próximas quanto à natureza e a função.

Este não é um trabalho singelo, pois exige desconstrução e abandono do antigo e re-construção e adoção do novo - o que nem sempre é fácil, pois uma idéia não morre para ser substituída por outra, simplesmente. O que acontece é que algumas certezas vão sendo questionadas, novas hipóteses vão se configurando e acabam por constituir-se em outras idéias. Assim, é o caminho do conhecimento e esse é o rumo das mudanças em educação (Hoffmann, 2002, p. 108).

A dificuldade apresentada em relação ao tempo, em parte, deve-se à estrutura anual da graduação. Os alunos, ao cursarem muitas disciplinas ao mesmo tempo, ficam exacerbados de leituras e trabalhos, o que não permite uma dedicação mais profunda a qualquer delas. Assim, despendem esforços de acordo com a necessidade de nota e com a dificuldade da disciplina. No que concerne ao professor, existe a dificuldade em dar conta dos trabalhos a serem corrigidos - analisados, comentados, repensados em termos de novas orientações para novas etapas - dentro da carga horária disponível, visto que trabalha, ao mesmo tempo, com várias turmas, na maioria das vezes numerosas.

Ainda, a resistência por parte de alguns alunos ao diferente não deixa de ser um fator altamente limitador. Os alunos precisam sentir que estão engajados em mudanças que irão fazer uma diferença genuína na vida de milhares de alunos e na própria sociedade; eles precisam sentir-se envolvidos por algo maior, que mereça o seu desapego às velhas e seguras práticas.

Todavia, tal não constitui uma missão simples, pois demanda a proposição de tarefas significativas e desafiadoras pela professora, de atividades que contextualizem a reflexão e imprimam novas características à atuação de cada um dos alunos no exercício da docência - para a qual se preparam. Ainda exige disponibilidade e tempo de cada um dos alunos, solicita redução dos mecanismos de resistência para o enfrentamento de situações novas, de práticas avaliativas diferenciadas, de reflexão sobre o trajeto percorrido e de proposição de novos caminhos.

Abandonar práticas que impregnam o cotidiano escolar há muito nem sempre é tarefa fácil. A diversificação de instrumentos postos a serviço da avaliação da aprendizagem dos alunos, que cursaram a disciplina de 
Ginástica Rítmica, exigiu de todos - professora e alunos - maiores esforços em sua consecução, uma vez que solicitavam a leitura crítica e analítica de textos, o estabelecimento de analogias entre informações, a proposição de soluções para situações problema, a criação de seqüências de ações para dar forma ao teoricamente discutido e analisado, o que demanda um longo e contínuo - mas nem sempre tranqüilo - processo de desequilíbrio e equilíbrio, que passam pela oferta de novas e inovadoras hipóteses.

Contudo, mesmo diante das dificuldades, pudemos observar que uma avaliação, implementada numa perspectiva diagnóstico-formativa, levou os alunos a valorizarem o diálogo e a partilha de saberes, a terem uma maior compreensão de suas conquistas, a melhor participarem do processo de construção de suas competências e habilidades, pela busca constante de superação das próprias dificuldades.

Nossa intenção foi de que o aluno mudasse os sentimentos em face da avaliação, reformulasse o conceito de avaliação e elaborasse uma coerência maior entre fala e ato, entre teoria e prática, pela implementação de mudanças no processo avaliativo, levando-o a refletir - na medida em que avança na edificação do conhecimento - e auxiliando-o na descoberta de novos saberes que o incitassem no aprimoramento gradual de sua atuação.

Entendemos que a escola, em todos os seus níveis e instâncias, precisa enfrentar seus desafios e readequar suas práticas - pedagógicas e avaliativas - de forma que possa promover o aluno nas dimensões do saber, saber fazer e saber ser e, acima de tudo, possa viabilizar uma educação compromissada com o exercício consciente e competente da profissão, bem como possa dar as condições necessárias para o exercício consciente da cidadania.

Desse modo, avanços e superações decorrem - de modo geral - de iniciativas as vezes tímidas e de passos geralmente pequenos, que têm como ponto de partida a conscientização e o envolvimento daqueles cuja tarefa é educar.

Finalmente, é possível um fazer diferente em relação à avaliação da aprendizagem... e, em conseqüência, é possível contribuir para a construção de um educador mais reflexivo que não mais compreende a avaliação como um processo punitivo e limitado, mas que o redimensiona como um processo que favorece os avanços e as superações quando o erro é utilizado como indicador diagnóstico para o re-direcionamento do ensinar e do aprender; reconhece no ensinar e no aprender um longo e contínuo processo de construção coletiva, que implica avanços e retrocessos, permanências e volubilidades, e que, até por isso, solicita reflexões e confrontações de saberes e fazeres, que suscitam uma maior compreensão 
do momento vivido e das ações necessárias às superações enunciadas; busca coerência entre seu saber e seu fazer, superando uma perspectiva meramente técnica e instrumental que vige ainda, de modo geral, na área de Educação Física, mesmo porque o respaldo teórico consistente é fundamental para a compreensão e para a transformação das ações.

Assim, comprometer-se de forma mais reflexiva e efetiva com a execução da obra educativa, compreendendo que o educador cresce com o aluno quando redimensiona constantemente a relação pedagógica, trabalhando de maneira mais dinâmica, olhando para a frente e acreditando que é possível avançar pela proposição de iniciativas simples, mas arrojadas e comprometidas com a efetivação de aprendizagens mais significativas, tendo a avaliação como uma bússola que orienta quanto ao caminho a ser tracejado - a construção e reconstrução dos saberes - e percebendo que a magia do avaliar está na descoberta da complexidade do ensinar (Hoffmann, 1999, p. 135), o que exige expectativa, iniciativa, coragem, disposição na procura constante de novos e inovadores conhecimentos.

\section{REFERÊNCIAS BIBLIOGRÁFICAS}

BARDIN, Laurence. Análise de conteúdo. Lisboa: Edições 70, 1977.

BRANDÃO, Carlos Rodrigues. Repensando a pesquisa participante. 2. ed. São Paulo: Brasiliense, 1985.

BRASIL. Ministério da Educação e do Desporto, Secretaria de Educação Fundamental. Parâmetros curriculares nacionais: Educação Física. Brasília: MEC/SEF, 1997.

HOFFMANN, Jussara M. L. Pontos e contrapontos: do pensar ao agir em avaliação. 3. ed. Porto Alegre: Mediação 1999.

Avaliação: mito \& desafio - uma perspectiva construtivista. 29.ed. Porto Alegre: Educação e Realidade, 2000.

Avaliar para promover: compromisso deste século. In: DEMO, Pedro; LA TAILLE, Yves de; HOFFMANN, Jussara. Grandes pensadores em educação: o desafio da aprendizagem, da formação moral e da avaliação. 2. ed. Porto Alegre: Mediação, 2002.

LUCKESI, Cipriano C. Avaliação da aprendizagem escolar. 9. ed. São Paulo: Cortez, 1999. 
PERRENOUD, Philippe. Avaliação: da excelência à regulação das aprendizagens - entre duas lógicas. Porto Alegre: Artes Médicas, 1999.

SOARES, Carmen L. et al. Educação Física: raízes européias e Brasil. Campinas: Autores Associados, 1994.

TRIVIÑOS, Augusto N. S. Introdução à pesquisa em ciências sociais: a pesquisa qualitativa em educação. São Paulo: Atlas, 1987.

Recebido em: junho 2006

Aprovado para publicação em: outubro 2006 